\title{
Salicylic Acid
}

National Cancer Institute

\section{Source}

National Cancer Institute. Salicylic Acid. NCI Thesaurus. Code C61934.

A beta hydroxy acid that occurs as a natural compound in plants. It has direct activity as an anti-inflammatory agent and acts as a topical antibacterial agent due to its ability to promote exfoliation. 